\title{
Reorienting attention and inhibition of return
}

\author{
DAVID J. PRIME \\ Université de Montréal, Montréal, Québec, Canada \\ TROY A. W. VISSER \\ University of British Columbia, Okanagan, Kelowna, British Columbia, Canada \\ and \\ LAWRENCE M. WARD \\ University of British Columbia, Vancouver, British Columbia, Canada
}

\begin{abstract}
In experiments examining inhibition of return (IOR), it is common practice to present a second cue at fixation during the cue-target interval. The purpose of this fixation cue is to reorient attention away from the cued location to ensure that the facilitative effects of spatial attention do not obscure IOR. However, despite their frequent use, relatively little is known about the relationship between fixation cues and IOR. In the present experiments, we examined the role of fixation cues by manipulating their presence in tasks that either did or did not require target identification. When the participants were required to either detect (Experiment 1A) or localize (Experiment 2A) a target, the magnitude of IOR was unaffected by the presence of a fixation cue. In contrast, when the participants were required to identify a target (Experiments 1B, 2B, and 3), IOR was observed only when a fixation cue was presented. This result was obtained regardless of the type of response that was required (two-alternative forced choice or go/no go). The effectiveness of the fixation cue in revealing IOR in these tasks is consistent with its putative role in reorienting attention away from the cued location.
\end{abstract}

Covert orienting of attention is often studied within the context of the cue-target paradigm. In this paradigm, the presentation of a spatially uninformative stimulus cue at the location of an upcoming visual target reduces target detection and discrimination reaction time (RT) when the cue-target stimulus onset asynchrony (SOA) is brief (see Wright \& Ward, 1998, for a review). This short-lived improvement in performance is believed to result from a reflexive shift of attention to the cued location. At longer SOAs, however, responses to targets at cued locations actually become slower than responses to targets at uncued locations (Posner \& Cohen, 1984). Posner, Rafal, Choate, and Vaughan (1985) labeled this later inhibitory effect "inhibition of return" (IOR). Since its discovery, IOR has been observed in a wide variety of experimental situations within the visual, auditory, and tactile modalities, as well as between modalities. IOR has also been observed across a variety of tasks, including detection, localization, and discrimination (see Klein, 2000, for a review). This ubiquity suggests that the mechanisms underlying IOR are important and general processes involved in the spatial selection of information.

Despite extensive research, the exact mechanisms underlying IOR have not yet been determined. When they

This research was supported by Natural Sciences and Engineering Research Council (NSERC) Discovery Grants to L.M.W. and T.A.W.V Correspondence concerning this article should be addressed to D. J. Prime, 303, 195 Côte Ste.-Catherine, Outremont, QC, H2V 2B1 Canada (e-mail: david_john_prime@yahoo.com). coined the term "inhibition of return," Posner et al. (1985) proposed that attention is reflexively oriented to the cued location and that, after reorienting to fixation, it is inhibited from returning to a previously attended location. They also suggested that this inhibition of attentional reorienting serves to bias the visual system to acquire novel information at new spatial locations. Although this account of IOR remains popular, competing accounts have also been proposed (for reviews, see Klein, 2000; Taylor \& Klein, 1998b, 2000). At present, no consensus has been reached regarding either the mechanisms of IOR or their functional significance. In fact, no consensus has yet been reached regarding which inhibitory cue effects should be classified as IOR. In particular, several authors have proposed that spatial and nonspatial inhibitory effects arise from different mechanisms (Fox \& de Fockert, 2001; Prime \& Ward, 2002; Taylor \& Klein, 1998a). Current evidence indicates that IOR may arise from a combination of inhibited perceptual processing (Handy, Jha, \& Mangun, 1999; McDonald, Ward, \& Kiehl, 1999; Prime \& Ward, 2004, 2006), a more conservative response criterion on valid trials relative to invalid trials (Ivanoff \& Klein, 2001), and inhibition of oculomotor programming (Ro, Pratt, \& Rafal, 2000). Given the evidence supporting both perceptual and response-related mechanisms, it has been proposed that IOR may arise from multiple mechanisms (Kingstone \& Pratt, 1999; Taylor \& Klein, 2000).

One reason for the current theoretical uncertainty is that many of the empirical characteristics of IOR have not yet been studied systematically. A variety of experimental 
variables have been shown to affect the presence, onset latency, and magnitude of IOR. Some of these factors are response task (see, e.g., Lupiáñez, Milán, Tornay, Madrid, \& Tudela, 1997), target intensity (see, e.g., Reuter-Lorenz, Jha, \& Rosenquist, 1996), target modality (Reuter-Lorenz et al., 1996), and the type of cue used (Riggio, Bello, \& Umiltà, 1998). However, relatively few studies have systematically examined how these variables interact. Such work is essential for integrating results from experiments that differ in a variety of factors (for an illustrative example of this approach, see Taylor \& Klein, 2000). To this end, we systematically examined the effect of the frequently used, but rarely studied, central fixation cue (also called a reorienting event) on visual IOR.

In all of Posner and Cohen's (1984) original IOR experiments, some manipulation was made to discourage the participants from maintaining attention at the cued location. This was done to ensure that the facilitative effects of spatial attention did not obscure any inhibitory aftereffects of the cue. In some experiments, a second central cue was presented at fixation prior to target onset. The purpose of this fixation cue was to reorient attention away from the cued location and back to fixation. In the years following Posner and Cohen's article, many studies have found that IOR can be obtained in the absence of a fixation cue, even when no other measures are taken to ensure that attention does not dwell at the cued location (see, e.g., Danziger \& Kingstone, 1999; Ivanoff \& Klein, 2001; McDonald et al., 1999). This suggests that fixation cues may be unnecessary for obtaining IOR, because the participants typically do not maintain their attention at the cued location.

Recently, Pratt and Fischer (2002) directly examined the role of fixation cues on both the time course and magnitude of IOR in an experiment utilizing a simple detection task. They found that the effect of fixation cues on IOR differed at short and long SOAs. At an SOA of $200 \mathrm{msec}$, reliable IOR was observed only when a fixation cue was presented in the time interval between cue and target. At longer SOAs, however, the magnitude of IOR was unaffected by the presence of a fixation cue. Although these results indicate that fixation cues are unnecessary at SOAs longer than $200 \mathrm{msec}$, there is evidence that this result may not generalize to all tasks or situations. For example, in the auditory modality, fixation cues are sometimes required for IOR to be observed, even at SOAs greater than 1 sec (Prime, Tata, \& Ward, 2003; Spence \& Driver, 1998; cf. Tata, Prime, McDonald, \& Ward, 2001). Similarly, in cross-modality situations, in which a cue in one modality is followed by a target in a different modality, fixation cues are used frequently (see, e.g., Spence \& Driver, 1998) and may be critical to obtaining IOR at all (McDonald \& Ward, 2003). In addition, fixation cues have been shown to be effective in revealing IOR in visual target-detection tasks with young children (MacPherson, Klein, \& Moore, 2003), the elderly (Castel, Chasteen, Scialfa, \& Pratt, 2003), and Alzheimer patients (Faust \& Balota, 1997).

In addition to these empirical results, there are also theoretical reasons to believe that fixation cues may be effective in modulating cue effects at SOAs longer than
$200 \mathrm{msec}$ in some visual tasks. When participants are required to make nonspatial target discriminations, IOR is either not observed at the SOAs tested (see, e.g., Pontefract \& Klein, 1988, as cited in Danziger \& Kingstone, 1999; Eimer, 1994; Hopfinger \& Mangun, 1998; Klein \& Taylor, 1994) or appears at longer cue-target SOAs than are required for target-detection or localization tasks (see, e.g., Lupiáñez et al., 1997; Lupiáñez \& Milliken, 1999, Lupiáñez, Milliken, Solano, Weaver, \& Tipper, 2001). To account for this, Klein (2000) proposed that the participants adjust an internal attentional control setting according to the difficulty of the task (for a similar proposal framed in terms of object files, see Lupiáñez et al., 2001). For more difficult tasks, more attentional resources are allocated to the task. According to this account, the more attentional resources are allocated to the task, the longer stimulus-driven attention will dwell at the cued location. For relatively easy tasks, such as suprathreshold target detection, attention will be allocated to the cued location for only a short duration. In more difficult tasks, such as identity-based discriminations, attention dwells at the cued location for longer durations. This, in turn, delays the appearance of IOR, either because IOR does not occur until attention is withdrawn from a location or because the facilitative effects of spatial attention mask the inhibitory effect of IOR. In support of this proposal, Klein cites evidence that the crossover point from attentional facilitation to IOR increases with task difficulty, as measured by the RT to the target (Klein, 2000, Figure 4).

If the time course of IOR is affected by attentional dwell time, it follows that IOR should be observed earlier if attention is reoriented away from the cued location before the target appears. This prediction, however, has received mixed support. Danziger and Kingstone (1999) compared the time course of IOR between conditions in which cues were either unpredictive or predicted that the target would be presented at a location one position clockwise from the cued location. In the latter case, it was assumed that the cue would initially draw attention reflexively to its location, followed by a voluntary shift of attention to the predicted target location. Consistent with the attentional dwell time hypothesis, IOR was observed earlier in the predictive cue condition than when the cue was completely unpredictive. However, this pattern of results was obtained only when participants were required to detect the onset of the target. When the participants were required to identify the target, IOR was not observed with either predictive or unpredictive cues. This result suggests that voluntarily shifting attention away from the cued location is not sufficient to produce IOR in a discrimination task.

Although the latter result may seem inconsistent with the attentional dwell time account, it is important to note that the cues in Danziger and Kingstone (1999) initiated a voluntary shift of attention. The attentional dwell time account, on the other hand, was proposed to account for the effects of stimulus-driven shifts of attention. This is important, because there is evidence that voluntary and stimulus-driven attention rely on independent systems (see, e.g., Juola, Koshino, \& Warner, 1995; Yantis, 1996) 
and, although the facilitatory effects of voluntary attention orienting can obscure IOR, it has been demonstrated that IOR is independent of voluntary attention orienting (see, e.g., Berger, Henik, \& Rafal, 2005; Lupiáñez et al., 2004). Thus, it is likely that the predictive cues used by Danziger and Kingstone resulted in a shift of voluntary attention without reorienting stimulus-driven attention from the cued location. Furthermore, the failure of the voluntary attention shift to affect the cuing effect indicates that the delayed onset of IOR in discrimination tasks relative to detection tasks does not arise from prolonged voluntary orienting toward the cued location. This is consistent with Klein's (2000) attentional dwell time hypothesis, which states that the attentional control setting determines the dwell time of stimulus-driven attention. According to this account, reorienting attention voluntarily in the predictive cue condition was effective in revealing IOR at a shorter SOA than in the unpredictive cue condition of Danziger and Kingstone's simple detection task, because stimulusdriven attention did not linger at the cued location in this undemanding task. In contrast, voluntary reorienting of attention failed to reveal IOR in the discrimination task because stimulus-driven attention continued to dwell at the cued location. Consequently, the possibility remains that the time course of IOR in discrimination tasks can be effectively modulated when stimulus-driven attention is drawn away from the cued location by another salient event, such as a fixation cue.

In the present study, we investigated the effectiveness of fixation cues in revealing IOR in situations in which it would not otherwise be observed. In the following experiments, we did this by examining the effect of the presence of a fixation cue in two types of tasks: attentiondemanding tasks that required target identification, and less attention-demanding tasks that did not require target identification. In Experiments $1 \mathrm{~A}$ and 1B, we compared a simple detection task to a form-discrimination task. The stimuli and timing parameters of these experimenters were based on pilot data and were chosen so that, in the absence of a fixation cue, IOR would be observed in the detection task but not in the discrimination task. According to Klein's attentional dwell time hypothesis, the lack of IOR in the discrimination task is due to attention dwelling at the cued location. On this basis, we predicted that presenting a fixation cue before target onset would draw attention away from the cued location and reveal IOR in the discrimination task. By contrast, we predicted that the fixation cue would not affect the magnitude of IOR in the detection task, because attention would not have been maintained at the cued location.

\section{EXPERIMENTS 1A AND 1B}

In Experiment 1A, the participants were asked to detect the onset of a peripheral target ( $\mathrm{a}$ " + " or an " $\mathrm{X}$ ") by pressing a key on the keyboard as quickly as possible. Targets were always preceded by the onset of a cue consisting of the brightening of a placeholder box centered on one of the potential target locations. There were two main conditions. In one, a fixation cue was interposed between the peripheral cue and the target; in the other, the fixation cue was omitted. Experiment $1 \mathrm{~B}$ was identical to Experiment 1A except that the participants were required to report the identity of the peripheral target.

Following a procedure similar to that used in Pratt et al. (2002), we also varied the SOA between the peripheral cue and the fixation cue. This was done for two reasons. One was to ensure that our results were comparable with those of Pratt et al. (2002). The other was to separate the "alerting" effects (see, e.g., Fernandez-Duque \& Posner, 1997; Posner, 1980) of the fixation cue from other influences it might have on IOR. It is known that presentation of a salient event prior to a target speeds responses by alerting the participants to prepare for the target onset. The magnitude of this effect grows larger as the interval between the alerting event and the target is increased. Thus, by manipulating the interval between the fixation cue and the target, we could determine whether the alerting effect of the fixation cue was related to the fixation cue's effect on IOR.

\section{Method}

Participants. All of the observers were students attending the University of Victoria who received course credit for participating. Twenty-two observers (15 female) took part in Experiment 1A and 28 observers ( 17 female) took part in Experiment 1B. All of the participants reported normal or corrected-to-normal vision. None were aware of the purpose of the experiment.

Apparatus and Stimuli. Stimuli were presented on a 17 -in. Sony Multiscan monitor (Model E240) running at a refresh rate of $100 \mathrm{~Hz}$, slaved to a Pentium 4 computer running Presentation software (Neurobehavioral Systems, Inc.). All of the stimuli were composed of dim, but clearly visible, gray pixels, and were presented on a black background. The viewing distance was $60 \mathrm{~cm}$. Location placeholders consisted of outline rectangles that subtended an area of approximately $1.5^{\circ} \times 1.5^{\circ}$ of visual angle. The fixation cue consisted of a solid gray circle with a diameter of approximately $1.0^{\circ}$. Targets were either a "+" or an "X" that subtended an area of approximately $0.75^{\circ}$ square.

Procedure. Experiments 1A and 1B differed only with regard to the participants' task. In Experiment 1A, the participants were required to detect the onset of the target; in Experiment 1B, they were required to discriminate target identity. Each experiment was divided into two blocks of 288 trials. In one block of trials (fixation cue present), a fixation cue was presented between the cue and the target. In the other block (fixation cue absent), the fixation cue was omitted. The order of the blocks was counterbalanced so that half of the participants performed the fixation cue present block first.

The sequence of events on each trial is diagrammed in Figure 1. Each trial began with presentation of a small fixation point at the center of the display flanked by two placeholder boxes - one to the left of the fixation and the other to the right. The placeholders remained on the display throughout the trial. The center-to-center separation between each placeholder and fixation was approximately $10^{\circ}$ of visual angle. The participants were instructed to focus their eyes on fixation and to maintain their gaze at this location for the remainder of the trial. ${ }^{1}$ After $500 \mathrm{msec}$, a cue was presented that consisted of the brightening of one of the two placeholders for $200 \mathrm{msec}$. The placeholders were brightened by increasing their thickness from 1 to 3 pixels. Cue location varied randomly, with the constraint that each location had to be cued equally often in a block of trials. The participants were instructed to ignore the cue because it did not predict the location of the subsequent target.

The SOA between the cue and the target was always $800 \mathrm{msec}$. However, the events that occurred between the offset of the cue and 


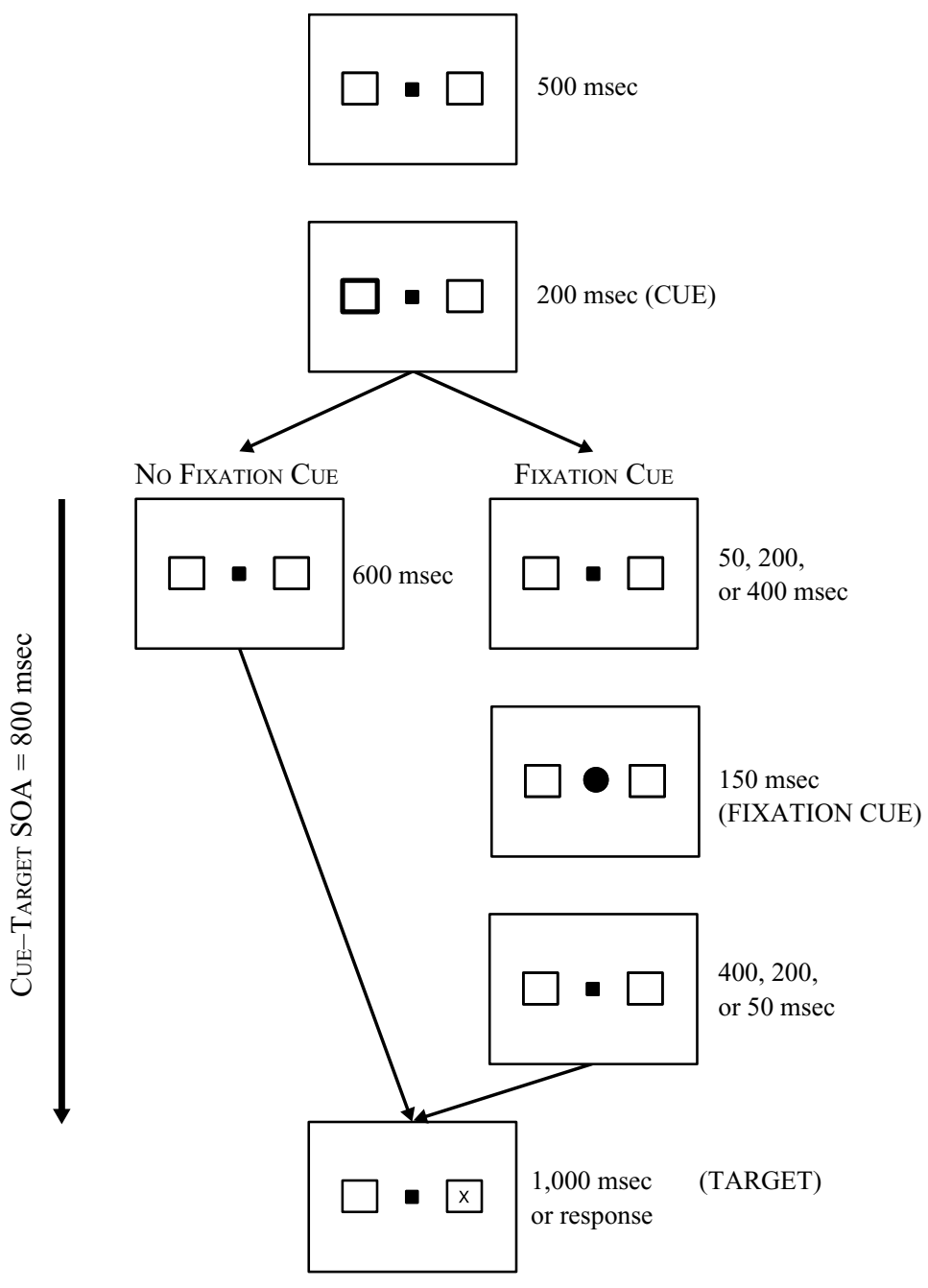

Figure 1. Schematic representation of events on each experimental trial. Events were identical across experiments; only target responses varied.

the onset of the target differed between blocks of trials. In the fixation cue absent block, offset of the cue was followed by a $600-\mathrm{msec}$ interval, during which only the fixation point and the placeholders were visible. In the fixation cue present block, the placeholders remained visible, but the fixation point was replaced by a gray disk (the fixation cue) 50,200, or $400 \mathrm{msec}$ after the offset of the peripheral cue. This yielded an SOA between the peripheral cue and the fixation cue of 250,400 , or $600 \mathrm{msec}$. The fixation cue remained on the display for $150 \mathrm{msec}$ and was followed by the reappearance of the fixation point for 400,250 , or $50 \mathrm{msec}$.

The target was presented inside one of the placeholder boxes. The choice of target shape and location varied randomly, with the constraint that each shape and location was used equally often in a block of trials. Critically, this assured that there was no predictive relationship between cue and target locations. Trials in which the target was presented at the same location as the cue were classified as valid trials. Trials in which the cue and the target were presented in different locations were classified as invalid trials. Targets remained on the display for 1,000 msec or until the observer made a response.

In Experiment $1 \mathrm{~A}$, the participants were instructed to respond to the onset of the target, regardless of its identity, by pressing the space bar on the computer keyboard as quickly as possible. In Experiment $1 \mathrm{~B}$, the participants were instructed to indicate whether the target was a "+" or an "X" by pressing one of two appropriately marked keys on the keyboard. Although speed was stressed, the participants were also cautioned to maintain a high level of accuracy in their responses. To give the participants performance feedback, the computer beeped on trials in which errors were made or in which responses were made too quickly or too slowly (less than $200 \mathrm{msec}$, or more than $1,000 \mathrm{msec}$ after target onset). In addition, to ensure that the participants did not try to anticipate the target onset, the target was omitted on $12.5 \%(36 / 288)$ of the trials. On these "catch" trials, the fixation dot and empty placeholders remained on the display for $1,000 \mathrm{msec}$ in place of the target.

At the end of the trial, the fixation dot disappeared for $700 \mathrm{msec}$, and then the next trial began automatically. After every 24 trials, the participants were given a chance to take a rest break before going on.

\section{Results}

Experiment 1A. Data from 1 participant were omitted from further analysis because the error rate and false alarm rate on catch trials were at least three times greater than those of any other participant (inclusion of their data does not substantively alter any of the findings reported below). False alarm and error rates were computed for the remain- 
Table 1

Mean Error Rates (in Percentages) for Experiments 1A and 1B

\begin{tabular}{|c|c|c|c|c|c|c|}
\hline \multirow[b]{3}{*}{ Experiment } & \multirow[b]{3}{*}{ Task } & \multirow{3}{*}{$\begin{array}{l}\text { Cue-Fixation } \\
\text { SOA (msec) }\end{array}$} & \multicolumn{4}{|c|}{ Cue Validity } \\
\hline & & & \multicolumn{2}{|c|}{ Valid } & \multicolumn{2}{|c|}{ Invalid } \\
\hline & & & $\% \mathrm{E}$ & SEM & $\% \mathrm{E}$ & SEM \\
\hline \multirow[t]{5}{*}{$1 \mathrm{~A}$} & Detection & 250 & 3.14 & 1.66 & 4.09 & 1.82 \\
\hline & & 400 & 3.81 & 1.37 & 1.51 & 0.79 \\
\hline & & 600 & 3.08 & 0.84 & 2.71 & 0.72 \\
\hline & & Present average & 3.35 & 1.15 & 2.67 & 0.95 \\
\hline & & Absent & 1.03 & 0.22 & 0.96 & 0.26 \\
\hline \multirow[t]{5}{*}{ 1B } & Discrimination & 250 & 4.76 & 0.66 & 4.07 & 0.69 \\
\hline & & 400 & 4.56 & 0.65 & 4.13 & 0.75 \\
\hline & & 600 & 3.78 & 0.68 & 5.00 & 0.74 \\
\hline & & Present average & 3.97 & 0.43 & 4.42 & 0.50 \\
\hline & & Absent & 3.05 & 0.34 & 4.05 & 0.41 \\
\hline
\end{tabular}

ing participants. False alarms were defined as responses on trials in which no target was presented. The false alarm rate was $2.47 \%$ in the fixation cue absent condition and $3.86 \%$ in the fixation cue present condition. This difference was not significant $[t(21)=0.80, p>.21]$.

Mean error rates as a function of cue validity and cuefixation SOA are listed in Table 1. Errors were defined as RTs of less than $200 \mathrm{msec}$ or more than 1,000 msec. Trials on which errors were made were discarded from RT analysis. Mean RTs at each cue-fixation SOA, as well as in the condition in which the fixation cue was omitted, are shown in Figure 2.

Preliminary analyses were conducted to determine whether mean RTs or error rates differed as a function of the SOA between the cue and the fixation cue for

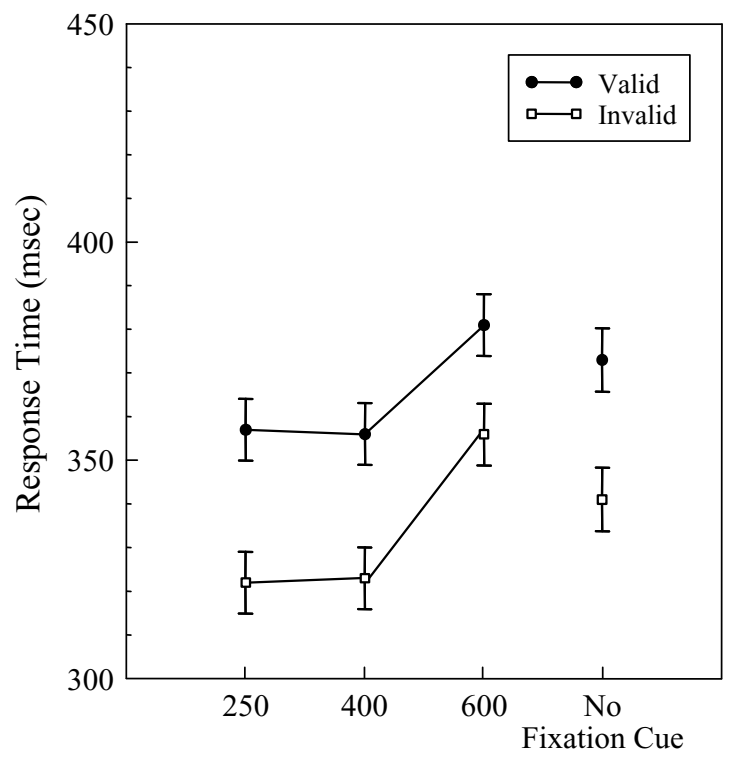

Cue-Fixation SOA

Figure 2. Target RTs as a function of cue-fixation SOA (250, $400,600 \mathrm{msec}$, or no fixation cue) and cue validity (valid, invalid) in Experiment 1A (target-detection task). Error bars represent one $95 \%$ within-subjects confidence interval calculated per Loftus and Masson (1994). the three fixation cue present conditions. Mean RTs and error rates were analyzed in separate 2 (cue validity: valid, invalid) $\times 3$ (cue-fixation SOA: 250,400 , $600 \mathrm{msec}$ ) within-subjects ANOVAs. The RT analysis revealed significant main effects of cue validity $[F(1,21)=$ 229.77, $\left.M S_{\mathrm{e}}=139.55, p<.001\right]$ and cue-fixation SOA $\left[F(2,42)=29.77, M S_{\mathrm{e}}=415.25, p<.001\right]$. The interaction between these factors did not approach significance $(p>.19)$, indicating that the validity effect did not vary as a function of cue-fixation SOA. We therefore collapsed across cue-fixation SOA in the subsequent analysis of the effect of fixation cue presence. The analysis of error rates revealed no significant main effects (all $p \mathrm{~s}>.09$ ), but a cue validity $\times$ cue-fixation SOA interaction $[F(2,42)=$ $\left.4.20, M S_{\mathrm{e}}=7.04, p<.03\right]$. The source of this interaction, however, was unclear, because there appeared to be no interpretable pattern of errors across conditions.

Examination of mean RTs in Figure 2 suggests that responses to validly cued targets were slower than to invalidly cued targets, indicating the presence of IOR. More importantly, this difference was similar in magnitude, regardless of whether a fixation cue was presented. To confirm this impression, mean RTs were analyzed in a 2 (cue validity) $\times 2$ (fixation cue: present, absent) withinsubjects ANOVA. Consistent with the presence of IOR, the analysis revealed a main effect of cue validity $[F(1,21)=$ 261.21, $M S_{\mathrm{e}}=81.44, p<.001$ ], indicating that mean RTs were significantly slower when targets were presented in the cued location than when they were presented in the uncued location. However, no other main effects or interactions were significant (all $p \mathrm{~s}>.50$ ), indicating that the magnitude of IOR was unaffected by the presence of the fixation cue. To determine whether these results were qualified by error data, mean error rates as a function of cue validity and presence/absence of a fixation cue were analyzed in a 2 (cue validity) $\times 2$ (fixation cue) withinsubjects ANOVA. This analysis revealed no significant main effects or interactions (all $p \mathrm{~s}>.05$ ).

Although the preliminary analysis of the RT data for three fixation cue present conditions did not reveal an interaction between cue-fixation SOA and cue validity, a significant main effect of cue-fixation SOA was obtained. As can be seen in Figure 2, RTs increased with the cue- 
fixation SOA. This effect most likely arises from a general alerting or warning effect of the fixation cue, which often increases with the SOA between the alerting and target stimuli (see, e.g., Fernandez-Duque \& Posner, 1997). In the present case, the interval between the fixation cue and the target decreases with increasing cue-fixation SOA. We would therefore expect that the alerting effect of the fixation cue would be greatest at the shortest cue-fixation SOA and that overall RTs would be fastest at this SOA. Furthermore, as the interval between the fixation cue and the target is decreased, RTs would approach those in the fixation cue absent condition, because the participants had progressively less time after onset of the fixation cue to prepare for the target. To determine whether this pattern of results was obtained, we compared mean RTs at each cuefixation SOA (collapsed across cue validity) to the mean $\mathrm{RT}$ in the fixation cue absent condition. This revealed that RTs were reliably faster at the $250-\mathrm{msec}[t(21)=2.94$, $p<.01]$ and $400-\mathrm{msec}[t(21)=2.93, p<.01]$ SOAs, but not statistically different at the 600 -msec SOA $[t(21)=$ $-1.787, p>.08]$ - a pattern consistent with the notion that the fixation cue led to alerting effects. One notable aspect of these results is that whether or not the fixation cue yielded alerting effects, similar levels of IOR were obtained. This suggests that the mechanisms underlying alerting effects do not influence those mechanisms responsible for generating IOR.

Experiment 1B. The false alarm rate was $0.76 \%$ in the fixation cue absent condition and $0.32 \%$ in the fixation cue present condition. This difference was not significant $[t(27)=0.94, p>.17]$.

Mean error rates as a function of cue validity and cuefixation SOA are listed in Table 1. Trials on which errors were made were discarded from RT analysis. Mean RTs at each cue-fixation SOA, as well as in the condition in which the fixation cue was omitted, are shown in Figure 3.

Preliminary analyses were conducted to determine whether mean RTs or error rates differed as a function of the SOA between the cue and the fixation cue. As in Experiment $1 \mathrm{~A}$, RTs and error rates were analyzed in 2 (cue validity: valid, invalid) $\times 3$ (cue-fixation SOA: 250,400 , $600 \mathrm{msec}$ ) within-subjects ANOVAs. The RT analysis revealed significant main effects of cue validity $[F(1,27)=$ $\left.37.39, M S_{\mathrm{e}}=232.38, p<.001\right]$ and cue-fixation SOA $\left[F(2,54)=32.90, M S_{\mathrm{e}}=291.96, p<.001\right]$. The interaction between these factors, however, was not significant $(p>.05)$, indicating that the validity effect did not vary as a function of cue-fixation SOA. Therefore, we again collapsed across cue-fixation SOA in the subsequent analysis of the effect of fixation cue presence. The analysis of error rates revealed no significant main effects or interactions (all $p \mathrm{~s}>.19$ ).

Examination of mean RTs in Figure 3 suggests that when the fixation cue was omitted, RTs were similar for both validly cued and invalidly cued targets. In contrast, when the fixation cue was present, RTs were slower to validly cued targets than to invalidly cued targets, indicating the presence of IOR. To confirm these impressions, mean RTs were analyzed in a 2 (cue validity) $\times 2$ (fixation cue:

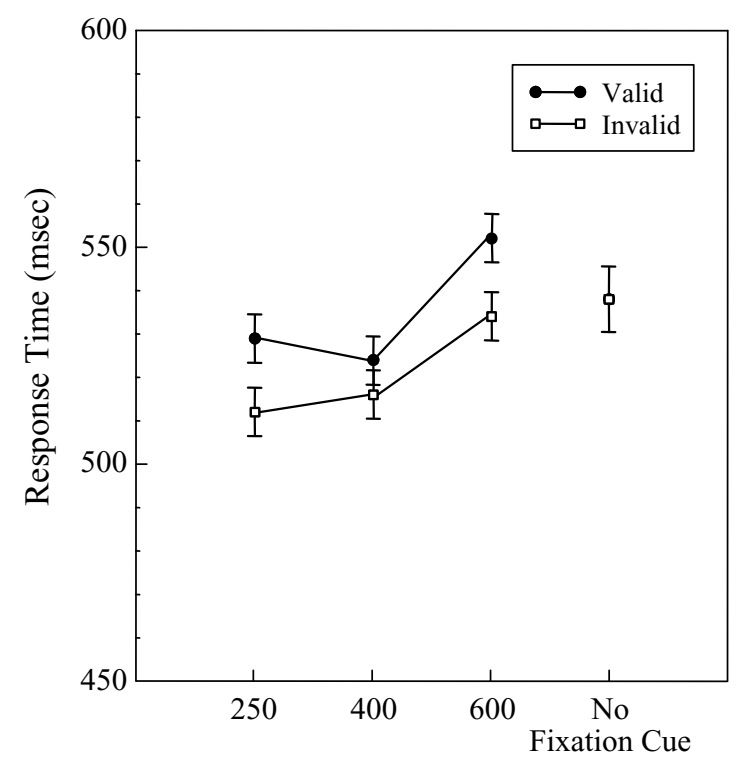

Cue-Fixation SOA

Figure 3. Target RTs as a function of cue-fixation SOA (250, $400,600 \mathrm{msec}$, or no fixation cue) and cue validity (valid, invalid) in Experiment 1B (target-discrimination task). Error bars represent one $95 \%$ within-subjects confidence interval calculated per Loftus and Masson (1994).

present, absent) within-subjects ANOVA. The analysis revealed a significant main effect of cue validity $[F(1,27)=$ $\left.4.32, M S_{\mathrm{e}}=357.78, p<.05\right]$, indicating that RTs to targets at uncued locations were faster than RTs to targets at cued locations. More importantly, the analysis also showed an interaction between cue validity and fixation cue $\left[F(1,27)=8.65, M S_{\mathrm{e}}=159.90, p<.01\right]$. Post hoc comparisons showed that when the fixation cue was omitted, there was no difference in RTs between validly cued and invalidly cued targets $[t(27)=0.07, p>.94]$, indicating that IOR was absent. In contrast, when a fixation cue was presented between the onset of the cue and the target, RTs to validly cued targets were significantly slower than RTs to invalidly cued targets $[t(27)=5.90, p<.001]$, indicating that IOR was present. To determine whether these results were qualified by error data, mean error rates as a function of cue validity and presence/absence of a fixation cue were analyzed in a 2 (cue validity) $\times 2$ (fixation cue) within-subjects ANOVA. This analysis revealed no significant main effects or interactions (all $p \mathrm{~s}>.05$ ).

As in Experiment 1A, a significant main effect of cuefixation SOA was obtained in the preliminary analysis. To determine whether alerting effects were found in Experiment 1B, we compared mean RTs at each cue-fixation SOA (collapsed across cue validity) to mean RTs in the no-reorienting event condition. This analysis revealed that RTs were reliably faster at the $250-\mathrm{msec}[t(27)=3.38$, $p<.01]$ and 400-msec $[t(27)=3.75, p<.001]$ SOAs, but not statistically different at the 600 -msec SOA $[t(27)=$ $-0.946, p>.35]$. Again, this pattern is consistent with the presence of alerting effects. Moreover, because IOR 
was consistently found across cue-fixation SOAs, it suggests that the presence of alerting effects was unrelated to whether or not IOR was obtained.

\section{Discussion}

The results of Experiment 1A, which showed that the presence of a fixation cue did not influence IOR when the participants were asked to detect a target, are consistent with earlier findings reported by Pratt and Fischer (2002). In contrast, the results of Experiment 1B, in which the participants were asked to discriminate target identity, showed that significant IOR was obtained only when a fixation cue was present. This difference is illustrated clearly by comparing the pattern of results shown in Figures 2 and 3 . To confirm this impression, the results from Experiments 1A and 1B were analyzed in a 2 (task: detection vs. discrimination) $\times 2$ (cue validity) $\times 2$ (fixation cue: present vs. absent) mixed-design ANOVA, which revealed a significant three-way interaction between these factors $\left[F(1,58)=7.07, M S_{\mathrm{e}}=115.20, p<.02\right]$.

These results are consistent with variable attention dwell time accounts of task-dependent variability in the onset of IOR. When IOR is not otherwise observed at a given cue-target SOA, presenting a fixation cue before target onset reveals the IOR effect. We suggest that the fixation cue captures attention, resulting in a shift of stimulus-driven attention away from the cued location and back to fixation. Conversely, when IOR is already established, fixation cues have no effect on the magnitude of IOR, presumably because attention has already been withdrawn from the cued location. This proposal is supported by the rapidity with which the fixation cue was able to alter the effect of cue validity. Validity did not interact with cue-fixation SOA, and the magnitude of the IOR effect was the same for all SOAs in Experiment 1B. This indicates that the effect of the fixation cue on IOR reached its maximum in no more than $200 \mathrm{msec}$ (the shortest fixation cue-target SOA in the present experiments). This is consistent with what is known about the ability of sudden onsets to orient attention rapidly and involuntarily (see, e.g., Jonides, 1981) and with earlier studies showing rapid onset of IOR under some experimental conditions (see, e.g., Collie, Maruff, Yucel, Danckert, \& Currie, 2000).

According to the attentional dwell time hypothesis (Klein, 2000), the differential effect of the fixation cue in the discrimination and detection tasks is due to the different demands each task places on attentional resources. However, it has also been shown that the nature of the response task can affect the time course of IOR (Khatoon, Briand, \& Sereno, 2002) and that the magnitude of IOR decreases with the number of possible responses (Pratt, Adam, \& O'Donnell, 2005). Thus, there are at least two clear differences between the detection and discrimination tasks employed in Experiments 1A and 1B that might explain why the fixation cue affected IOR in the former but not the latter. First, whereas a single keypress was required in the detection task, the participants had to make a two-alternative forced choice response in the discrimination task. Thus, it is possible that differences in the re- sponse requirements may underlie the disparate findings from Experiments 1A and 1B. A second possibility is that differences between the experiments arose from differences in target processing requirements. In the detection task, responding to the onset of the target was sufficient to make a correct response. However, in the discrimination task, correct responses depended on target identification. Thus, the influence of the fixation cue may vary, depending on whether the target must be identified or not. This possibility is consistent with both Klein's (2000) attentional control setting proposal and Lupiáñez et al.'s (2001) finding that the delayed onset of IOR in discrimination tasks is related to the nature of the perceptual discrimination required.

To disentangle these options, we investigated the role of response requirements and target processing in modulating the influence of the fixation cue on IOR. In Experiment $2 \mathrm{~A}$, we employed the same stimuli and procedures as in Experiments $1 \mathrm{~A}$ and 1B, but required the participants to localize the target to either the left or right of fixation. Here, a correct response depended on simply determining the location of the target. As in Experiment 1A, the identity of the target ("+" or "X") was irrelevant. However, the task necessitated choosing between two alternative responses, as in Experiment 1B. This allowed us to investigate whether the effect of the fixation cue depended on the number of potential responses. In Experiment 2B, we again employed the same stimuli and procedures as in Experiments 1A and 1B, but asked the participants to respond only when a particular target stimulus appeared (a go/no-go task). Here, a correct response depended on identifying the target stimulus, as in Experiment 1B, but necessitated only one response, as in Experiment 1A. This allowed us to investigate whether the effect of the fixation cue depended on the nature of target processing.

\section{EXPERIMENTS 2A AND 2B}

\section{Method}

Participants. All of the observers were students attending the University of Victoria who received course credit for participating. Twenty-nine undergraduate students (15 female) participated in Experiment $2 \mathrm{~A}$ and another 29 undergraduate students (15 female) participated in Experiment 2B. All of the participants reported normal or corrected-to-normal vision. None of the observers had participated in Experiments 1A or 1B, and none were aware of the purpose of the experiment.

Apparatus and Stimuli. The apparatus and stimuli were identical to those used in Experiments 1A and 1B.

Procedure. The procedure was identical to that of Experiments $1 \mathrm{~A}$ and $1 \mathrm{~B}$ except for differences in response requirements. In Experiment $2 \mathrm{~A}$, the participants were required to indicate whether the target (which was equally likely to be a "+" or an "X") appeared to the left or right of fixation by pressing one of two appropriately marked keys on the keyboard. In Experiment 2B, the participants were told to respond by pressing the space bar if a "+" target appeared, but to refrain from pressing any key if an " $\mathrm{X}$ " target appeared. Each target appeared equally often.

\section{Results}

Experiment 2A. The false alarm rate was $0.52 \%$ in the condition without a fixation cue and $0.42 \%$ in the condi- 
Table 2

Mean Error Rates (in Percentages) for Experiments 2A and 2B

\begin{tabular}{|c|c|c|c|c|c|c|}
\hline \multirow[b]{3}{*}{ Experiment } & \multirow[b]{3}{*}{ Task } & \multirow{3}{*}{$\begin{array}{l}\text { Cue-Fixation } \\
\text { SOA (msec) }\end{array}$} & \multicolumn{4}{|c|}{ Cue Validity } \\
\hline & & & \multicolumn{2}{|c|}{ Valid } & \multicolumn{2}{|c|}{ Invalid } \\
\hline & & & $\% \mathrm{E}$ & SEM & $\% \mathrm{E}$ & SEM \\
\hline \multirow[t]{5}{*}{$2 \mathrm{~A}$} & Localization & 250 & 0.75 & 0.23 & 0.99 & 0.32 \\
\hline & & 400 & 1.00 & 0.33 & 1.11 & 0.28 \\
\hline & & 600 & 0.35 & 0.22 & 0.91 & 0.24 \\
\hline & & Present average & 0.70 & 0.20 & 1.00 & 0.17 \\
\hline & & Absent & 0.92 & 0.23 & 1.27 & 0.23 \\
\hline \multirow[t]{5}{*}{$2 \mathrm{~B}$} & Go/no go & 250 & 0.53 & 0.25 & 0.92 & 0.34 \\
\hline & & 400 & 0.71 & 0.29 & 0.86 & 0.32 \\
\hline & & 600 & 0.73 & 0.36 & 1.21 & 0.43 \\
\hline & & Present average & 0.66 & 0.20 & 0.96 & 0.24 \\
\hline & & Absent & 1.24 & 0.36 & 1.23 & 0.32 \\
\hline
\end{tabular}

tion with a fixation cue. This difference was not significant $[t(28)=0.24, p>.81]$.

Mean error rates as a function of cue validity and cue-fixation SOA are listed in Table 2. Trials on which errors were made were discarded from RT analysis. Mean RTs at each cue-fixation SOA, as well as in the condition in which the fixation cue was omitted, are shown in Figure 4.

As in Experiments 1A and 1B, preliminary analyses were conducted to determine whether mean RTs or error rates differed as a function of the SOA between the cue and the fixation cue. Mean RTs and error rates were analyzed in 2 (cue validity: valid, invalid) $\times 3$ (cue-fixation SOA: 250, 400, $600 \mathrm{msec}$ ) within-subjects ANOVAs. The RT analysis revealed significant main effects of cue va-

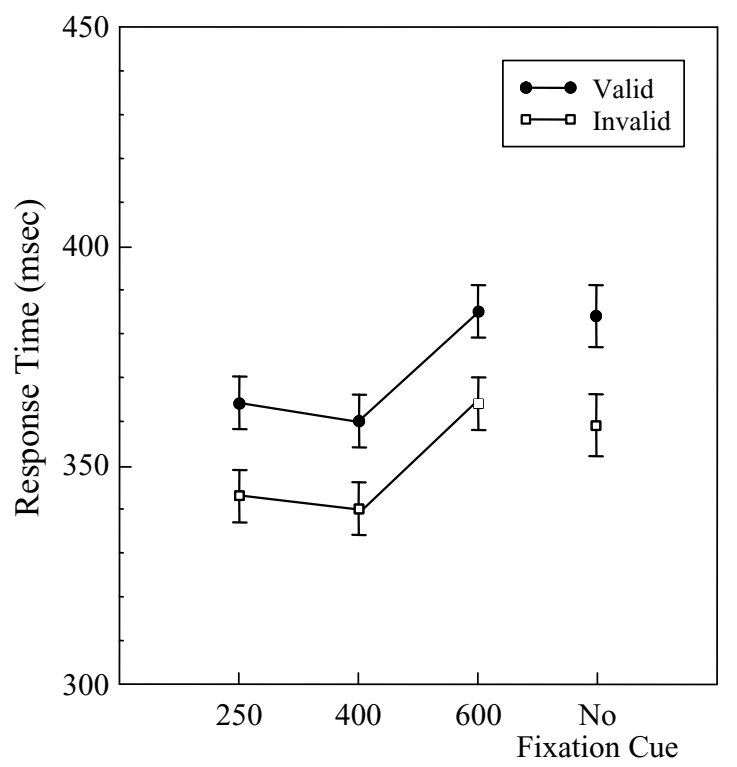

Cue-Fixation SOA

Figure 4. Target RTs as a function of cue-fixation SOA (250, $400,600 \mathrm{msec}$, or no fixation cue) and cue validity (valid, invalid) in Experiment 2A (target-localization task). Error bars represent one $95 \%$ within-subjects confidence interval calculated per Loftus and Masson (1994). lidity $\left[F(1,28)=58.40, M S_{\mathrm{e}}=303.53, p<.001\right]$ and cue-fixation SOA $\left[F(2,56)=30.39, M S_{\mathrm{e}}=341.38, p<\right.$ $.001]$. As before, the interaction between these factors, however, was not significant $(p>.05)$, indicating that the validity effect did not vary as a function of cue-fixation SOA. We therefore collapsed across cue-fixation SOA in the subsequent analysis of the effect of fixation cue presence. The analysis of error rates revealed no significant main effects or interactions (all $p \mathrm{~s}>.15$ ).

Examination of mean RTs in Figure 4 suggests that responses to validly cued targets were slower than to invalidly cued targets, indicating the presence of IOR. More importantly, this difference was similar in magnitude, regardless of whether a fixation cue was presented. To confirm this impression, mean RTs were analyzed in a 2 (cue validity) $\times 2$ (fixation cue: present, absent) withinsubjects ANOVA. Consistent with the presence of IOR, the analysis revealed a main effect of cue validity $[F(1,28)=$ $120.74, M S_{\mathrm{e}}=120.89, p<.001$ ], indicating that mean RTs were significantly slower when targets were presented in the cued location than when they were presented in the uncued location. There was also a main effect of fixation cue $\left[F(1,28)=5.75, M S_{\mathrm{e}}=749.69, p=.023\right]$, indicating that overall RTs were faster when the fixation cue was present. However, the interaction between cue validity and fixation cue was not significant $(p>.21)$, suggesting that the magnitude of IOR was unaffected by the presence of the fixation cue. To determine whether these results were qualified by error data, we analyzed mean error rates as a function of cue validity and presence/absence of a fixation cue in a 2 (cue validity) $\times 2$ (fixation cue) within-subjects ANOVA. This analysis revealed no significant main effects or interactions (all $p \mathrm{~s}>.05$ ).

Consistent with Experiments 1A and 1B, a significant main effect of cue-fixation SOA was obtained in the preliminary analysis. To determine whether alerting effects were found in Experiment 2A, we compared mean RTs at each cue-fixation SOA (collapsed across cue validity) to mean RTs in the no-reorienting event condition. This analysis revealed that RTs were reliably faster at the $250-\mathrm{msec}[t(28)=2.91, p<.01]$ and $400-\mathrm{msec}[t(28)=$ $3.97, p<.001]$ SOAs, but not statistically different at the $600-\mathrm{msec} \operatorname{SOA}[t(28)=-0.689, p>.49]$. This pattern is 
consistent with the presence of alerting effects. Moreover, because IOR was consistently found across cue-fixation SOAs, it suggests that the presence of alerting effects was unrelated to whether or not IOR was obtained.

Experiment 2B. The false alarm rate was $0.10 \%$ in the condition with no fixation cue and $0.21 \%$ in the conditions with a fixation cue. This difference was not significant $[t(28)=0.57, p>.57]$.

Mean error rates as a function of cue validity and cuefixation SOA are listed in Table 2. Trials on which errors were made were discarded from RT analysis. Mean RTs at each cue-fixation SOA, as well as in the condition in which the fixation cue was omitted, are shown in Figure 5.

Preliminary analyses were again conducted to determine whether mean RTs or error rates differed as a function of the SOA between the cue and the fixation cue. The RT analysis revealed significant main effects of cue validity $\left[F(1,28)=13.90, M S_{\mathrm{e}}=899.29, p=.001\right]$ and cue-fixation SOA $\left[F(2,56)=15.98, M S_{\mathrm{e}}=378.39, p<\right.$ $.001]$. The interaction between these factors did not approach significance $(p>.37)$, indicating that the validity effect did not vary as a function of cue-fixation SOA. We therefore collapsed across cue-fixation SOA in the subsequent analysis of the effect of fixation cue presence. The analysis error rates revealed no significant main effects or interactions (all $p \mathrm{~s}>.30$ ).

Examination of mean RTs in Figure 5 suggests that when the fixation cue was omitted, RTs were similar for both validly cued and invalidly cued targets. In contrast, with the fixation cue, RTs were slower to validly cued targets than to invalidly cued targets, indicating the presence

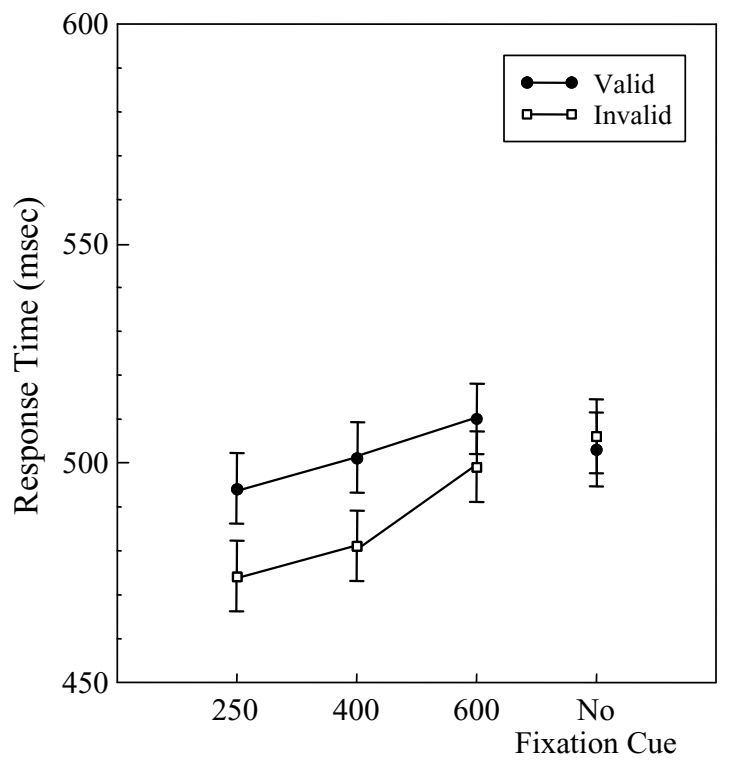

Cue-Fixation SOA

Figure 5. Target RTs as a function of cue-fixation SOA (250, $400,600 \mathrm{msec}$, or no fixation cue) and cue validity (valid, invalid) in Experiment 2B (target go/no-go task). Error bars represent one $95 \%$ within-subjects confidence interval calculated per Loftus and Masson (1994). of IOR. To confirm these impressions, mean RTs were analyzed in a 2 (cue validity) $\times 2$ (fixation cue) withinsubjects ANOVA. The analysis revealed a significant main effect of fixation cue $\left[F(1,29)=4.84, M S_{\mathrm{e}}=775.13\right.$, $p=.036]$, indicating that overall RTs were faster when the fixation cue was present than when it was omitted. More importantly, the analysis also showed an interaction between cue validity and fixation cue $[F(1,28)=19.84$, $\left.M S_{\mathrm{e}}=149.23, p<.01\right]$. Post hoc comparisons showed that when the fixation cue was omitted, there was no difference in RTs between targets at cued and uncued locations $[t(28)=0.60, p>.55]$, indicating that IOR was absent. In contrast, when a fixation cue was presented between the onset of the cue and the target, RTs at uncued locations were significantly faster than at cued locations $[t(28)=3.76, p=.001]$, indicating that significant IOR was present. To determine whether these results were qualified by error data, mean error rates as a function of cue validity and presence/absence of a fixation cue were analyzed in a 2 (cue validity) $\times 2$ (fixation cue) withinsubjects ANOVA. This analysis revealed no significant main effects or interactions (all $p s>.17$ ).

As in all of the previous experiments, a significant main effect of cue-fixation SOA was obtained in the preliminary analysis. To determine whether alerting effects were present in Experiment 2B, we compared mean RTs at each cue-fixation SOA (collapsed across cue validity) to mean RTs in the no-reorienting event condition. This analysis revealed that RTs were reliably faster at the $250-\mathrm{msec}$ $[t(28)=3.61, p<.01]$ and $400-\mathrm{msec}[t(28)=2.342, p<$ .03] SOAs, but not statistically different at the 600-msec SOA $[t(28)=0.02, p>.98]$. This pattern replicates the results of the previous experiments and is consistent with the presence of alerting effects. Moreover, because IOR was consistently found across cue-fixation SOAs, it suggests that the presence of alerting effects was unrelated to whether or not IOR was obtained.

\section{Discussion}

In Experiments $1 \mathrm{~A}$ and $1 \mathrm{~B}$, we found that a fixation cue did not influence the magnitude of IOR in a detection task, but did influence the magnitude of IOR in a discrimination task. The goal of Experiment 2A was to determine whether or not this arose from the requirement to choose between one of two response alternatives in our discrimination task. The results argue against this assertion. When the participants had to localize a target stimulus to the left or right of fixation, the fixation cue had no influence on the magnitude of IOR. This contrasts sharply with the results of Experiment $1 \mathrm{~B}$, in which the participants also had to make a twoalternative forced choice discrimination of a target stimulus, but in which there was a substantial influence of the fixation cue on IOR. Thus, it must be concluded that the influence of the fixation cue is not attributable simply to the requirement to make a two-alternative forced choice response.

In Experiment 2B, we examined an alternative hypothesis: that the influence of the fixation cue on the magnitude of IOR in the discrimination task arose from the requirement to identify the stimulus. To test this, we used a "go/ 
no-go" task, in which the participants were asked to press a key when one type of target appeared, but to refrain from making a response if a second type of target appeared. If the effect of the fixation cue is modulated by the requirement to identify a stimulus, it was expected that making the response contingent on stimulus identification would yield a large effect of the fixation cue on the magnitude of IOR. Exactly this pattern of results was observed; IOR was found only when the fixation cue was present. These findings are broadly similar to those from Experiment 1B, in which the participants were asked to choose a response based on the identity of the target. Taken together with previous results (e.g., Lupiáñez et al., 1997), the present results provide compelling evidence that IOR onset is delayed in tasks that require stimulus identification and that fixation cues are effective in revealing IOR at SOAs in which it would not otherwise be observed.

\section{EXPERIMENT 3}

In the previous experiments, the presence of the fixation cue was manipulated between experimental blocks. Thus, it is possible that the participants adopted different strategies for fixation cue present and fixation cue absent blocks. Consequently, the distinctly different patterns of results obtained when the fixation cue was present or absent may not have arisen from the presence of the cue per se but rather from differences in participant strategies. We therefore conducted a third experiment that was essentially identical to Experiment $1 \mathrm{~B}$ except that presence of the fixation cue varied randomly across trials. In addition, we also monitored eye position, to ensure that participants complied with the instruction to maintain eye gaze at the central fixation point throughout the trial.

\section{Method}

Participants. Eighteen undergraduate students ( 10 female $)$ at the University of British Columbia participated. All received course credit or a small honorarium for participating. None had participated in any of the earlier experiments.

Apparatus and Stimuli. The stimuli were presented on a 19-in. ViewSonic monitor running at a refresh rate of $100 \mathrm{~Hz}$, slaved to a Pentium 4 computer running Presentation software. The viewing distance was $50 \mathrm{~cm}$. The stimuli were essentially identical to those used in the previous experiments.

Procedure. The procedure was identical to that of Experiment 1B except for the following differences. First, trials with and without fixation cues were randomly interspersed within blocks, so that $50 \%$ of trials had a fixation cue. Second, the participants' eye movements were monitored during the experiment using electro-oculogram (EOG) recordings. Trials were excluded from the analysis if an eye movement of greater than $1^{\circ}$ was made during the interval between cue onset and target offset. Third, the number of trials was reduced to 256 (eight blocks of 32 trials) to reduce the potential impact of fatigue on performance. Fourth, because variations in cue-fixation SOA did not have an impact on performance in previous experiments, we used only one interval in the present experiment: $400 \mathrm{msec}$. Finally, the no-target catch trials were eliminated.

\section{Results}

The percentage of trials rejected due to eye movements was $12.9 \%$ in the fixation cue absent condition and $12.6 \%$
Table 3

Mean Error Rates (in Percentages) for Experiment 3

\begin{tabular}{cccccc}
\hline & \multicolumn{4}{c}{ Cue Validity } \\
\cline { 2 - 3 } \cline { 5 - 6 } Fixation Cue & $\% \mathrm{E}$ & $S E M$ & & \multicolumn{2}{c}{ Invalid } \\
\cline { 2 - 5 } & 6.17 & 0.98 & & 8.16 & 1.41 \\
Present & 6.23 & 1.32 & & 5.91 & 1.13 \\
Absent & 7.23 &
\end{tabular}

in the fixation cue present condition. This difference was not significant $[t(17)=0.42, p>.68]$. Mean error rates as a function of fixation cue presence/absence and cue validity are listed in Table 3 . Trials on which errors were made were discarded from RT analysis. Mean RTs are shown as in Figure 4 as a function of fixation cue presence/absence and cue validity.

Examination of mean RTs in Figure 6 suggests that when the fixation cue was omitted, RTs were similar for both validly cued and invalidly cued targets. In contrast, when the fixation cue was present, RTs were slower to validly cued targets than to invalidly cued targets, indicating the presence of IOR. To confirm these impressions, mean RTs were analyzed in a 2 (cue validity) $\times 2$ (fixation cue: present, absent) within-subjects ANOVA. The analysis revealed a significant main effect of fixation cue $[F(1,17)=$ $\left.7.20, M S_{\mathrm{e}}=297.27, p<.02\right]$, indicating that fixation cue had an alerting effect and RTs were faster when a fixation cue was present. More importantly, the analysis also showed an interaction between cue validity and fixation cue $\left[F(1,17)=6.21, M S_{\mathrm{e}}=409.90, p<.03\right]$. Post hoc comparisons showed that when the fixation cue was omit-

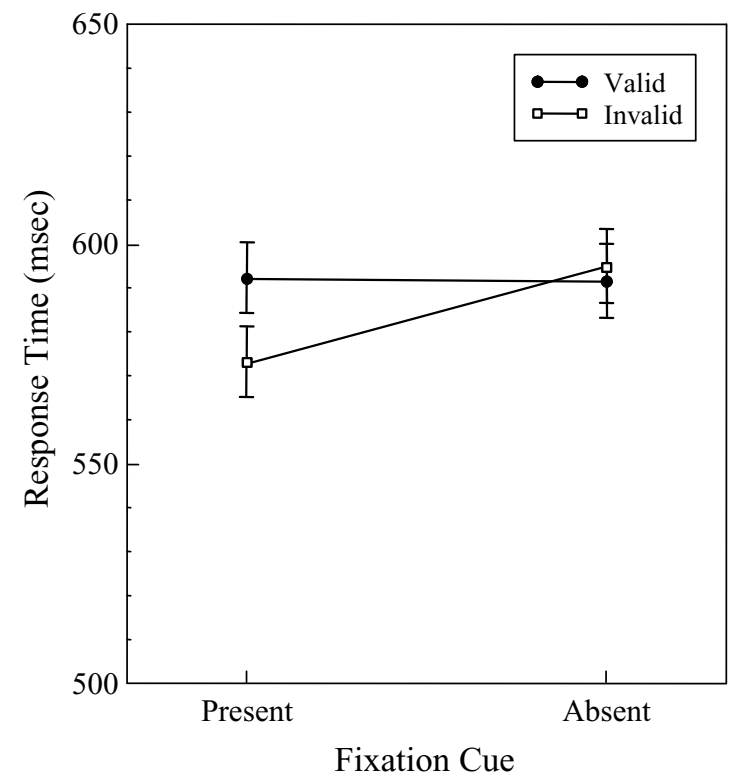

Figure 6. Target RTs as a function of cue fixation (present, absent) and cue validity (valid, invalid) in Experiment 3 (targetdiscrimination task). Error bars represent one $95 \%$ withinsubjects confidence interval calculated per Loftus and Masson (1994). 
ted, there was no difference in RTs to validly cued and invalidly cued targets $[t(17)=0.65, p>.51]$, indicating that IOR was absent. In contrast, when a fixation cue was presented between the onset of the cue and target, RTs to invalidly cued targets were significantly faster than RTs to validly cued targets $[t(17)=3.24, p<.01]$, indicating that significant IOR was present. To determine whether these results were qualified by error data, mean error rates as a function of cue validity and presence/absence of a fixation cue were analyzed in a 2 (cue validity) $\times 2$ (fixation cue) within-subjects ANOVA. This analysis revealed no significant main effects or interactions (all $p \mathrm{~s}>.08$ ).

\section{Discussion}

In Experiment 3, we replicated the principal finding of Experiment $1 \mathrm{~B}$ by obtaining robust IOR in a discrimination task when a fixation cue was used, but no IOR when a fixation cue was omitted. This demonstrates that these results are not due to strategic effects arising from the between-blocks manipulation of fixation cue presence used in Experiment 1B. Furthermore, the exclusion of trials on which eye movements were made ensured that the RT results did not arise from differences in overt eye movements between conditions. Instead, considered across experiments, the results argue compellingly that fixation cues can be effective in revealing IOR in situations in which it would not otherwise be observed.

\section{GENERAL DISCUSSION}

In the present experiments, we examined the effect of central fixation cues on IOR in tasks that either required stimulus identification (Experiments 1B, 2B, and 3) or did not (Experiments $1 \mathrm{~A}$ and 2A). When the participants were required to either detect (Experiment 1A) or localize (Experiment 2A) the target, we found that the magnitude of the IOR effect was not affected by the presence of a fixation cue. These results replicate and extend those of Pratt and Fischer (2002). The lack of an effect of the presence of a fixation cue on the magnitude of IOR in these tasks is consistent with the belief that fixation cues capture attention and reorient it to fixation. If the interval between the cue and target is sufficiently long for attention to have been withdrawn and for IOR to be established, fixation cues should have no effect on the observed cuing effect. When the tasks required the participants to identify the target (Experiments 1B, 2B, and 3), however, IOR was only observed when a fixation cue was presented between the cue and the target. This result was obtained regardless of the type of response that was required (two-alternative forced choice or go/no go). The effectiveness of the fixation cue in revealing IOR in these tasks is consistent with the proposal that the delayed onset or failure to obtain IOR in experiments utilizing nonspatial discrimination tasks arises from attention being maintained at the cued location (Klein, 2000).

In addition to their effect on the presence of IOR in Experiments 1B, 2B, and 3, fixation cues also had a main effect on RT in all of the present experiments. In Experi- ments 1 and 2, RTs were shorter for the two shorter cuefixation SOAs than for the fixation cue absent condition. No significant differences in RT were found between the fixation cue absent condition and the longest cue-fixation SOA condition. This facilitatory effect on RT is consistent with the alerting effects of spatially uninformative stimuli, which often increase with the SOA between the alerting and target stimuli (see, e.g., Fernandez-Duque \& Posner, 1997).

Taken together, the present results indicate that fixation cues have two separate effects on performance. First, regardless of the task, fixation cues serve as general alerting signals, resulting in faster responses than when no fixation cue is presented. Second, fixation cues reveal IOR in identity-based discrimination tasks at cue-target SOAs at which no IOR effect is observed in the absence of fixation cues. This is consistent with the conventional notion that the fixation cue reflexively orients attention from the cued location back to fixation.

Pragmatically, our findings demonstrate the utility of fixation cues in IOR experiments employing discrimination tasks. Indeed, although the role of the fixation cue is rarely acknowledged, there are many examples of its effectiveness in revealing IOR in discrimination tasks (see, e.g., Cheal \& Chastain, 1999; Kingstone \& Pratt, 1999; Pratt \& Abrams, 1999; Pratt, Kingstone, \& Khoe, 1997; Prime \& Ward, 2004). In fact, we are not aware of any published visual discrimination experiment using the cue-target paradigm in which IOR was not obtained when a fixation cue was used. In contrast, when a fixation cue is not presented, there have been a number of failures to obtain IOR in discrimination tasks, even at cue-target SOAs of up to $1 \mathrm{sec}$ (see, e.g., Pontefract \& Klein, 1988, as cited in Danziger \& Kingstone, 1999; Eimer, 1994; Hopfinger \& Mangun, 1998; Klein \& Taylor, 1994; Lupiáñez et al., 2001, Experiment 3, no-distractor condition; Milliken, Lupiáñez, Roberts, \& Stevanovski, 2003, no-temporalbias condition). This is not to say that fixation cues are always necessary for IOR to be observed in discrimination tasks (see Lupiáñez et al., 1997; Lupiáñez \& Milliken, 1999; Lupiáñez et al., 2001). However, consistent with Klein's attention dwell time hypothesis, the observed onset of IOR in such studies is later than in comparable detection task experiments.

More importantly, our results also have implications for theories of stimulus-driven attention orienting and IOR. Uncertainty regarding the presence and time course of IOR in identity-based discrimination tasks has had considerable impact on the theoretical debate regarding the mechanisms underlying IOR (see, e.g., Klein, 2000; Klein \& Taylor, 1994; Lupiáñez et al., 2001). According to Klein's (2000) attentional dwell time hypothesis, the observed time of IOR onset is determined by the duration for which stimulus-driven attention dwells at the cued location. This suggests that manipulations that promote a stimulus-driven shift of attention away from the cued location will reveal IOR at SOAs at which it would not otherwise be observed. The observed effectiveness of fixation cues in revealing IOR in the present study confirms this 
prediction. Therefore, we suggest that, in the absence of a fixation cue, attention continued to dwell at the cued location in the present discrimination task experiments and that the fixation cue reflexively oriented attention back to fixation. Although this conclusion is consistent with voluminous evidence that sudden stimulus onsets attract attention in a stimulus-driven manner (see Wright \& Ward, 1998, for a review), other accounts are possible. An anonymous reviewer suggested that it is possible that the alerting effect of the fixation cue may, in some unspecified way, be responsible for revealing IOR. The present results argue against this possibility. An alerting effect was observed only at the two earlier cue-fixation SOAs tested. Nevertheless, fixation cues were effective in revealing IOR at all three of the SOAs tested. In light of this, the most parsimonious explanation for the present results is that the fixation cues reoriented stimulus-driven attention away from the cued location and back to fixation. Without the facilitative effects of attention at the cued location, IOR could then be observed.

When Klein originally proposed the attentional dwell time hypothesis, he did not specify the mechanisms responsible for disengaging stimulus-driven attention from the cued location in the absence of a fixation cue. The results of Danziger and Kingstone (1999) demonstrated that voluntarily allocating attention to another spatial location is not sufficient. However, there are numerous other possibilities. One is that attention may be disengaged from the cued location in a completely involuntary or automatic fashion. For example, the facilitatory effect of attention may simply decay over time, or an automatic disengagement and shift of attention may occur after a period of time determined by the attentional control setting. Alternatively, executive control from the anterior attention system may be required for attention to be disengaged from the cued location. This suggestion is consistent with empirical phenomena such as contingent capture (Folk, Remington, \& Johnston, 1992), which illustrate the influence of top-down attentional control on stimulus-driven attentional systems. It is also consistent with numerous theoretical models of attention that include mechanisms by which executive processes can influence the stimulusdriven attention-orienting system (see, e.g., Shipp, 2004). Recently, Klein, Castel, and Pratt (2006) have provided evidence that the limited capacity executive attention system is involved in disengaging attention from the cued location. In their study, Klein et al. found that requiring participants to maintain a verbal memory load during the cue-target interval delayed the appearance of IOR. Consistent with the present results, this delay only occurred when a central fixation cue was not used. This implies that executive control processes are involved in disengaging attention from the cued location in the absence of fixation cues. However, they do not necessarily indicate that disengaging attention is a conscious, voluntary act akin to voluntarily attending to the location indicated by a symbolic cue.

One final aspect of the data to be discussed concerns the lack of attentional facilitation on RTs in the fixation cue absent conditions in Experiments 1B, 2B, and 3. If, in the absence of a fixation cue, attention continued to dwell at the cued location, it might be expected that responses to targets at this location would be facilitated, relative to uncued targets. Given the abundant evidence that stimulus cues do attract attention and facilitate RT (see, e.g., Wright \& Ward, 1998) and that fixation cues do reorient attention and eliminate attentional facilitation (Faust \& Balota, 1997; MacPherson et al., 2003), the most likely explanation is that attention was first allocated to the cued location and then reoriented to fixation in Experiments 1B, 2B, and 3. However, the cue-target SOA ( $800 \mathrm{msec})$ used in the present experiments may be near the crossover point from attentional facilitation to IOR. The lack of a significant cue effect in the fixation cue absent conditions may be the result of facilitatory and inhibitory processes canceling each other within trials. An alternative possibility is that attention may have been reoriented back to fixation on some portion of the trials, but not others. Summed across trials, this combination of inhibitory (attention reoriented) and facilitatory (attention not reoriented) trials may have yielded the small, nonsignificant, net facilitation observed.

Although the present experiments demonstrate that fixation cues are effective in revealing IOR, it remains to be shown exactly what factors determine the time course of attentional facilitation and IOR in various experimental situations, and how these factors interact. A multitude of factors have been shown to influence the effect of stimulus cues on RT, including response task (e.g., Lupiáñez et al., 1997), the presence of distractors (Lupiáñez \& Milliken, 1999), the number of potential target locations (Birmingham, Visser, Snyder, \& Kingstone, 2006), the informative value of the cue (Wright \& Richard, 2000), the range of cue-target SOAs used (Cheal \& Chastain, 2002), the probability of the target being presented at a short or long SOA (Milliken et al., 2003), and the emotional valence of cues (Fox, Russo, \& Dutton, 2002). What is less understood is how these factors interact. Both Klein (2000) and Lupiáñez et al. (1997; Lupiáñez \& Milliken, 1999) have made significant efforts in this direction by providing accounts of IOR that take into account the role of task demands in modulating the time course of stimulus-driven cue effects. As illustrated in the present work, such accounts can provide a cogent explanation for a range of data obtained across various experimental situations. However, what is needed is a more comprehensive theory of IOR that can account for many other factors that we know are important. Such theoretical work will require further empirical investigations that examine how combinations of factors jointly determine performance in cue-target paradigms. Ultimately, such efforts will help us better understand how information is selected from the visual environment.

\section{REFERENCES}

Berger, A., Henik, A., \& Rafal, R. (2005). Competition between endogenous and exogenous orienting of visual attention. Journal of Experimental Psychology: General, 134, 207-221.

Birmingham, E., Visser, T. A. W., Snyder, J. J., \& Kingstone, A. 
(2006). Inhibition of return: Unraveling a paradox. Manuscript submitted for publication.

Castel, A. D., Chasteen, A. L., Scialfa, C. T., \& Pratt, J. (2003). Adult age differences in the time course of inhibition of return. Journals of Gerontology, 58B, P256-P259.

Cheal, M., \& Chastain, G. (1999). Inhibition of return: Support for generality of the phenomenon. Journal of General Psychology, 126, 375-390.

Cheal, M., \& Chastain, G. (2002). Timing of facilitatory and inhibitory effects of visual attention. Visual Cognition, 9, 969-1002.

Collie, A., Maruff, P., Yucel, M., Danckert, J., \& Currie, J. (2000). Spatiotemporal distribution of facilitation and inhibition of return arising from the reflexive orienting of covert attention. Journal of Experimental Psychology: Human Perception \& Performance, 26, 1733-1745.

DanZiger, S., \& Kingstone, A. (1999). Unmasking the inhibition of return phenomenon. Perception \& Psychophysics, 61, 1024-1037.

EIMER, M. (1994). An ERP study on visual spatial priming with peripheral onsets. Psychophysiology, 31, 154-163.

FAust, M. E., \& Balota, D. A. (1997). Inhibition of return and visuospatial attention in healthy older adults and individuals with dementia of the Alzheimer type. Neuropsychology, 11, 13-29.

Fernandez-Duque, D., \& Posner, M. I. (1997). Relating the mechanisms of orienting and alerting. Neuropsychologia, 35, 477-486.

Folk, C. L., Remington, R. W., \& Johnston, J. C. (1992). Involuntary covert orienting is contingent on attentional control settings. Journal of Experimental Psychology: Human Perception \& Performance, 18, 1030-1044.

Fox, E., \& DE FocKerT, J.-W. (2001). Inhibitory effects of repeating color and shape: Inhibition of return or repetition blindness? Journal of Experimental Psychology: Human Perception \& Performance, 27, 798-812.

Fox, E., Russo, R., \& Dutton, K. (2002). Attentional bias for threat: Evidence for delayed disengagement from emotional faces. Cognition \& Emotion, 16, 355-379.

Handy, T. C., Jha, A. P., \& Mangun, G. R. (1999). Promoting novelty in vision: Inhibition of return modulates perceptual-level processing. Psychological Science, 10, 157-161.

Hopfinger, J. B., \& Mangun, G. R. (1998). Reflexive attention modulates processing of visual stimuli in human extrastriate cortex. Psychological Science, 9, 441-447.

IVANOFF, J., \& KLEIN, R. M. (2001). The presence of a nonresponding effector increases inhibition of return. Psychonomic Bulletin \& Review, 8, 307-314.

JONIDES, J. (1981). Voluntary versus automatic control over the mind's eye's movement. In J. [B.] Long \& A. [D.] Baddeley (Eds.), Attention and performance $I X$ (pp. 187-203). Hillsdale, NJ: Erlbaum.

Juola, J. F., Koshino, H., \& Warner, C. B. (1995). Tradeoffs between attentional effects of spatial cues and abrupt onsets. Perception \& Psychophysics, 57, 333-342.

Khatoon, S., Briand, K. A., \& Sereno, A. B. (2002). The role of response in spatial attention: Direct versus indirect stimulus-response mappings. Vision Research, 42, 2693-2708.

Kingstone, A., \& Pratt, J. (1999). Inhibition of return is composed of attentional and oculomotor processes. Perception \& Psychophysics, 61, 1046-1054.

KLeIN, R. M. (2000). Inhibition of return. Trends in Cognitive Sciences, 4, 138-147.

Klein, R. M., Castel, A. D., \& Pratt, J. (2006). The effects of memory load on the time course of inhibition of return. Psychonomic Bulletin \& Review, 13, 294-299.

KLeIN, R. M., \& TAYlor, T. L. (1994). Categories of cognitive inhibition, with reference to attention. In D. Dagenbach \& T. H. Carr (Eds.), Inhibitory processes in attention, memory, and language (pp. 113150). San Diego: Academic Press.

Loftus, G. R., \& Masson, M. E. J. (1994). Using confidence intervals in within-subject designs. Psychonomic Bulletin \& Review, 1, 476490

Lupiáñez, J., Decaix, C., Siéroff, E., Chokron, S., Milliken, B., \& BARTOLOMEO, P. (2004). Independent effects of endogenous and exogenous spatial cueing: Inhibition of return at endogenously attended target locations. Experimental Brain Research, 159, 447-457.
Lupiáñez, J., Milán, E. G., Tornay, F. J., Madrid, E., \& Tudela, P. (1997). Does IOR occur in discrimination tasks? Yes, it does, but later. Perception \& Psychophysics, 59, 1241-1254.

LuPiáÑEZ, J., \& MilLIKEN, B. (1999). Inhibition of return and the attentional set for integrating versus differentiating information. Journal of General Psychology, 126, 392-418.

Lupiáñez, J., Milliken, B., Solano, C., Weaver, B., \& Tipper, S. P. (2001). On the strategic modulation of the time course of facilitation and inhibition of return. Quarterly Journal of Experimental Psychology, 54A, 753-773.

MacPherson, A. C., Klein, R. M., \& Moore, C. (2003). Inhibition of return in children and adolescents. Journal of Experimental Child Psychology, 85, 337-351.

McDonald, J. J., \& Ward, L. M. (2003, April). Crossmodal consequences of involuntary spatial attention and inhibition of return. Poster presented at the annual meeting of the Cognitive Neuroscience Society, New York.

McDonald, J. J., Ward, L. M., \& Kiehl, K. A. (1999). An event-related brain potential study of inhibition of return. Perception \& Psychophysics, 61, 1411-1423.

Milliken, B., Lupiáñez, J., Roberts, M., \& Stevanovski, B. (2003). Orienting in space and time: Joint contributions to exogenous spatial cuing effects. Psychonomic Bulletin \& Review, 10, 877-883.

Posner, M. I. (1980). Orienting of attention. Quarterly Journal of Experimental Psychology, 32, 3-25.

PosNer, M. I., \& CoHEN, Y. (1984). Components of visual orienting. In H. Bouma \& D. G. Bouwhuis (Eds.), Attention and performance X: Control of language processes (pp. 531-556). Hillsdale, NJ: Erlbaum.

Posner, M. I., Rafal, R. D., Choate, L. S., \& Vaughan, J. (1985). Inhibition of return: Neural basis and function. Cognitive Neuropsychology, 2, 211-228.

Pratt, J., \& Abrams, R. A. (1999). Inhibition of return in discrimination tasks. Journal of Experimental Psychology: Human Perception \& Performance, 25, 229-242.

Pratt, J., Adam, J., \& O'Donnell, C. (2005). Response selection influences inhibition of return. European Journal of Cognitive Psychology, 17, 319-328.

Pratt, J., \& Fischer, M. H. (2002). Examining the role of the fixation cue in inhibition of return. Canadian Journal of Experimental Psychology, 56, 294-301.

Pratt, J., Kingstone, A., \& KhoE, W. (1997). Inhibition of return in location- and identity-based choice decision tasks. Perception \& Psychophysics, 59, 964-971.

PRIME, D. J. (2004). Electrophysiological investigations of inhibition of return across tasks. Unpublished doctoral dissertation, University of British Columbia, Vancouver.

Prime, D. J., TATA, M. S., \& WARD, L. M. (2003). Event-related potential evidence for attentional inhibition of return in audition. NeuroReport, 14, 393-397.

Prime, D. J., \& WARD, L. M. (2002). Auditory frequency-based inhibition differs from spatial IOR. Perception \& Psychophysics, 64, 771784 .

Prime, D. J., \& WARD, L. M. (2004). Inhibition of return from stimulus to response. Psychological Science, 15, 272-276.

PRIME, D. J., \& WARD, L. M. (2006). Cortical expressions of inhibition of return. Brain Research, 1072, 161-174.

Reuter-Lorenz, P. A., JHA, A. P., \& Rosenquist, J. N. (1996). What is inhibited in inhibition of return? Journal of Experimental Psychology: Human Perception \& Performance, 22, 367-378.

Riggio, L., Bello, A., \& Umiltà, C. (1998). Inhibitory and facilitatory effects of cue onset and offset. Psychological Research, 61, 107-118.

Ro, T., Pratt, J., \& Rafal, R. D. (2000). Inhibition of return in saccadic eye movements. Experimental Brain Research, 130, 264-268.

SHIPP, S. (2004). The brain circuitry of attention. Trends in Cognitive Sciences, 8, 223-230.

SPEnCE, C., \& Driver, J. (1998). Inhibition of return following an auditory cue: The role of central reorienting events. Experimental Brain Research, 118, 352-360.

Tata, M. S., Prime, D. J., McDonald, J. J., \& Ward, L. M. (2001). Transient spatial attention modulates distinct components of the auditory ERP. NeuroReport, 12, 3679-3682.

TAYLOR, T. L., \& KLEIN, R. M. (1998a). Inhibition of return to color: 
A replication and nonextension of Law, Pratt, and Abrams (1995) Perception \& Psychophysics, 60, 1452-1456.

TAYLOR, T. L., \& KLEIN, R. M. (1998b). On the causes and effects of inhibition of return. Psychonomic Bulletin \& Review, 5, 625-643.

TAYLOR, T. L., \& KLEIN, R. M. (2000). Visual and motor effects in inhibition of return. Journal of Experimental Psychology: Human Perception \& Performance, 26, 1639-1656.

Wright, R. D., \& RichaRD, C. M. (2000). Location cue validity affects inhibition of return of visual processing. Vision Research, $\mathbf{4 0}$, 2351-2358.

WRIGHT, R. D., \& WARD, L. M. (1998). The control of visual attention. In R. D. Wright (Ed.), Visual attention (pp. 132-186). New York: Oxford University Press.

YANTIS, S. (1996). Attentional capture in vision. In A. F. Kramer,
M. G. H. Coles, \& G. D. Logan (Eds.), Converging operations in the study of visual selective attention (pp. 45-76). Washington, DC: American Psychological Association.

\section{NOTE}

1. Although eye movements were not monitored in these experiments, we have obtained equivalent results to Experiments 1A and 1B in experiments utilizing event-related potentials in which eye movements were monitored (Prime, 2004; Prime \& Ward, 2004, 2006). See also Experiment 3 .

(Manuscript received December 29, 2003;

revision accepted for publication January 25,2006 .) 